\title{
Neuronal Polarity
}

\author{
Sabina Tahirovic and Frank Bradke \\ Max Planck Institute of Neurobiology, Axonal Growth and Regeneration, \\ Am Klopferspitz 18, 82152 Martinsried, Germany \\ Correspondence: fbradke@neuro.mpg.de
}

The assembly of functional neuronal networks in the developing animal relies on the polarization of neurons, i.e., the formation of a single axon and multiple dendrites. Breaking the symmetry of neurons depends on cytoskeletal rearrangements. In particular, axon specification requires local dynamic instability of actin and stabilization of microtubules. The polarized cytoskeleton also provides the basis for selective trafficking and retention of cellular components in the future somatodendritic or axonal compartments. Hence, these mechanisms are not only essential to achieve neuronal polarization, but also to maintain it. Different extracellular and intracellular signals converge on the regulation of the cytoskeleton. Most notably, Rho GTPases, PI3K, Ena/VASP, cofilin and SAD kinases are major intracellular regulators of neuronal polarity. Analyzing polarity signals under physiological conditions will provide a better understanding of how neurons can be induced to repolarize under pathological conditions, i.e., to regenerate their axons after central nervous system (CNS) injury.

$\mathrm{O}$ ne ambitious aim in cellular biology is to unravel the molecular mechanisms driving cellular asymmetry and polarization. The polarity of neurons is particularly dramatic as neurons undergo complex morphological rearrangements to assemble into neuronal circuits and propagate signals. They start as round neuronal spheres, gradually adopting a complex morphology by forming one long axon and several shorter dendrites to eventually connect to other neurons via synapses. Neuronal compartments segregate into molecularly and functionally distinct zones. For example, signal input takes place at the postsynaptic densities where a chemical signal elicits electric postsynaptic potentials. These potentials are integrated along the dendritic tree and cell body to trigger an action potential arising at the axon hillock and propagating further along the axon. At their terminals, the electrical signal is reconverted into a chemical signal by the release of synaptic vesicles containing neurotransmitter.

Neurons maintain their polarity throughout life by different intracellular mechanisms and molecular signals. During the last decade, cell biological and molecular approaches helped to discover many of the molecules and signaling mechanisms regulating neuronal polarity (Yoshimura et al. 2006; Arimura and Kaibuchi 2007; Witte and Bradke 2008). The aim of this article is to summarize the current

Editors: Rong Li and Bruce Bowerman

Additional Perspectives on Symmetry Breaking in Biology available at www.cshperspectives.org

Copyright (C) 2009 Cold Spring Harbor Laboratory Press; all rights reserved; doi: 10.1101/cshperspect.a001644

Cite this article as Cold Spring Harb Perspect Biol 2009;1:a001644 
knowledge and principles of breaking neuronal symmetry to generate functional neurons, and to discuss the future challenges in the field. The article covers two different topics: intrinsic mechanisms that govern symmetry breaking in the absence of external cues (in vitro systems) and the role of extracellular signaling in the establishment of neuronal polarity in vivo.

\section{MODELS OF NEURONAL POLARITY}

The two basic in vitro systems to study neuronal polarity are rodent embryonic hippocampal pyramidal neurons and postnatal cerebellar granule neurons. Hippocampal neurons are typically isolated from rat embryonic day (E) 18 embryos when the generation of pyramidal neurons is complete. Cerebellar granule neurons are typically isolated from early postnatal (P) cerebellar cortex (P4-P10). At the time of isolation, some cerebellar granule and hippocampal neurons already contain neurites, but during the dissociation procedure, these neurites are lost. Cells are re-set and start their development in culture as round, presumably symmetrical spheres.

In vitro systems are instrumental to study intracellular and molecular mechanisms during neuronal polarization.

\section{Hippocampal Neurons}

Studies from Banker and colleagues established dissociated rodent hippocampal neurons as a basic model system for neuronal asymmetry (Craig and Banker 1994; Kaech and Banker 2006). After dissociating and culturing hippocampal neurons on a two-dimensional substrate (most commonly used are polylysine and laminin), they maintain their intrinsic ability to develop two distinct cellular compartments: a single axon and several dendrites. This sequence of polarity events follows well described morphological changes (Fig. 1A,B) (Dotti et al. 1988). Neuronal development starts with round spheres that spread a lamellipodium around the cell body and stably attach to the substrate (shortly after plating; stage 1). These round spheres later transform into cells containing several neurites (12-24 h; stage 2), which are decorated with dynamic growth cones at their tips. Neurites at this early developmental stage show characteristic alternations of growth and retraction. The major polarity event is when one of these equally long neurites starts to grow rapidly to become the axon (24-48 h; stage 3 ). The next step is the morphological development of the remaining short neurites into dendrites ( $>3-4 \mathrm{~d}$; stage 4$)$ and functional polarization of axons and dendrites, including synapse formation ( $>1$ wk in culture; stage 5 ). Dendritic spines are formed at later stages $(>2 \mathrm{wk}$ in culture; stage 6).

One of the major advantages of this culture system is the ability of dissociated neurons to develop their morphological and functional polarity in vitro. This takes place under strictly controlled cell culture conditions, separated from the complexity of the nervous system. Furthermore, cultured neurons are well suited for cell biological manipulations and provide sufficient protein amounts to perform biochemical experiments.

\section{Cerebellar Granule Neurons}

An alternative system to study neuronal polarity is cerebellar granule neurons (Powell et al. 1997; Zmuda and Rivas 1998). These neurons exhibit a unique morphology characterized by two long axons (parallel fibers) and several short dendrites. Morphological development of cultured cerebellar granule neurons is depicted in Figure 1C,D (Powell et al. 1997; Zmuda and Rivas 1998). Cerebellar granule neurons start their development as round cells bearing short protrusions (24 h; stage 1 ) and continue by elongating a single neurite (24-48 h, unipolar; stage 2). Subsequently, a second neurite forms at the opposite side of the cell body $(>2-3 \mathrm{~d}$, bipolar; stage 3$)$. One of the processes elongates further and starts branching ( $>3-4 \mathrm{~d}$; stage 4$)$, resembling the T-shape morphology of parallel fiber axons of cerebellar granule neurons in vivo. Next, this axon elongates further and 
Neuronal Polarity

A

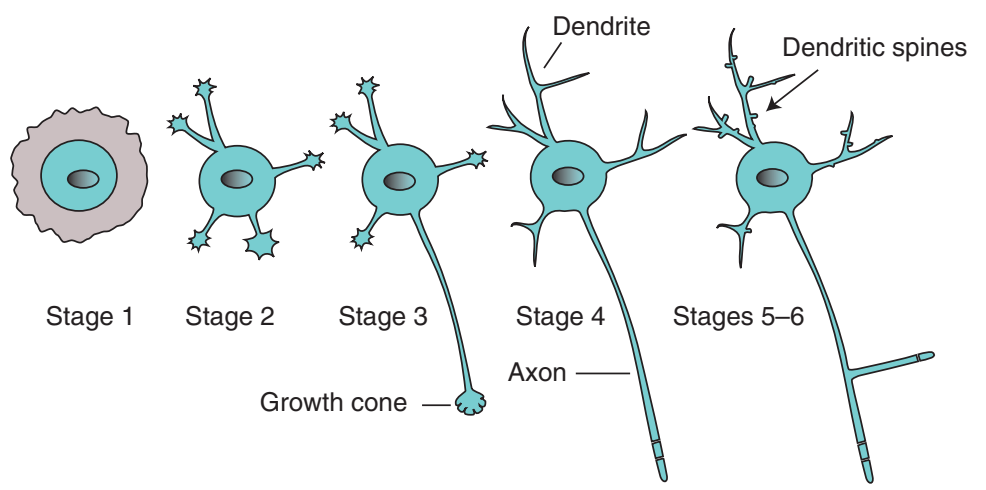

B
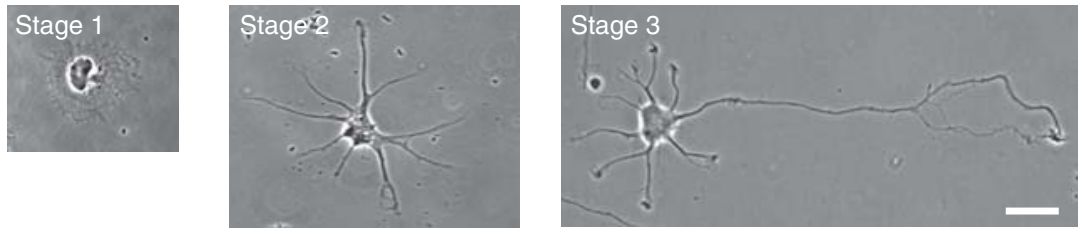

C

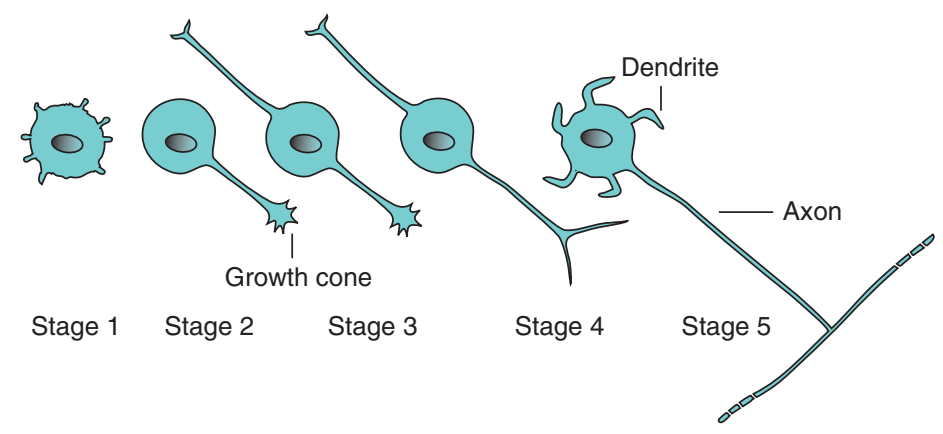

D
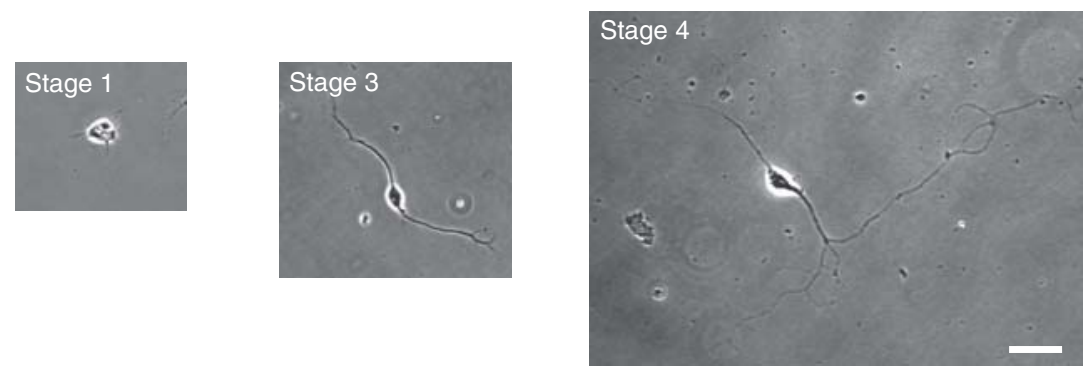

Figure 1. Neuronal polarization in cultured neurons. Developmental stages in cultured rodent embryonic hippocampal neurons $(A, B)$ and postnatal cerebellar granule neurons $(C, D)$. (A) Hippocampal neurons transform from round cells bearing lamellipodia (Stage 1) into multipolar cells (Stage 2). One neurite enlarges its growth cone and extends rapidly to become the axon (Stage 3). The remaining shorter neurites will develop into dendrites (Stage 4). This is followed by functional maturation and formation of dendritic spines and synapses (Stages 5-6). (B) Phase-contrast images of cultured hippocampal neurons in stages 1,2, and 3. Scale bar, $20 \mu \mathrm{m}$. (C) Shortly after plating, cerebellar granule neurons protrude several filopodia (Stage 1) and then start extending one process (Stage 2). From the opposite side of the cell body, another process develops: The granule neuron adopts bipolar morphology bearing two axons (Stage 3). One of the two axons elongates further and starts branching (Stage 4), while the other axon retracts and shorter dendrites form around the cell body (Stage 5). (D) Phase-contrast images of cultured cerebellar granule neurons in stages 1,3 , and 4 . Scale bar, $20 \mu \mathrm{m}$. 
dendrites develop around the cell body (>4-5 d; stage 5).

In vitro development of cerebellar granule neurons resembles developmental stages observed in vivo (Powell et al. 1997). Cerebellar granule neurons continue to develop in vivo until 2-3 weeks after birth. This makes dissociated cerebellar neurons well suited as a model of postnatal development. It is also a commonly used culture system to study the influence of inhibitory molecules relevant for axon regeneration (Erturk et al. 2007). As several million cerebellar granule cells exist in the postnatal rodent brain, it constitutes an ideal system for biochemical studies and functional assays.

\section{THE ROLE OF THE CYTOSKELETON IN NEURONAL POLARITY}

The cytoskeleton both establishes and maintains polarity in neurons (Witte and Bradke 2008). Actin filaments and microtubules have functional properties that make them uniquely suited to determine and regulate polarity, not only in neurons, but also in other polarizing cells (Li and Gundersen 2008). First, actin filaments and microtubules rapidly convert molecular signals into structural changes modulating cell shape. Second, actin filaments and microtubules possess an intrinsic polarity (Li and Gundersen 2008).

Of central importance for axon formation and neuronal polarity is the specialized, highly motile cellular compartment at the tips of growing axons, termed growth cone (Fig. 2A,B). This structure supports growth by sensing environmental cues (Dickson 2002) and transducing those signals to the cytoskeleton. The axonal growth cone is composed of a central region filled with organelles and microtubules and a peripheral, highly dynamic, actin-rich region containing lamellipodia and filopodia (Fig. 2A) (Forscher and Smith 1988; Dehmelt and Halpain 2004; Ishikawa and Kohama 2007). Lamellipodia are broad veil-like cellular protrusions that contain branched actin filaments. Filopodia are thin protrusions made out of unbranched and parallel F-actin bundles. Barbed (fast-growing) ends of actin filaments are oriented toward the rim and

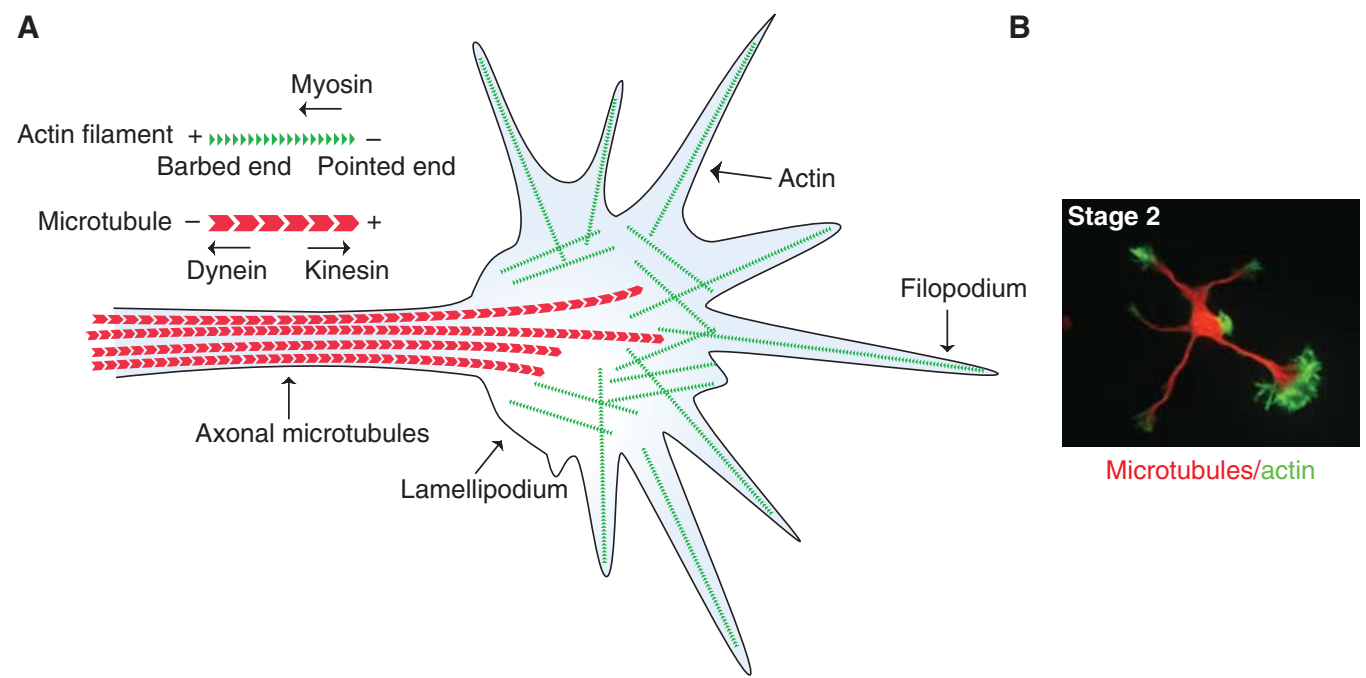

Figure 2. The growth cone cytoskeletal structure. (A) Illustration of an axonal growth cone. Microtubules (red) distributed along the axonal shaft protrude into the central region of the growth cone. The growth cone is enriched in F-actin (green) that is organized into long bundles forming filamentous protrusions, filopodia, or veil-like sheets of branched actin forming lamellipodia. Lamellipodia and filopodia are important for growth cone dynamics. (B) Immunocytochemical image of a stage-2 hippocampal neuron bearing an enlarged growth cone in one of the neurites. The actin cytoskeleton is stained in green and microtubules in red. 
pointed (slow-growing) ends toward the base of the growth cone (Fig. 2A). G-actin subunits continuously incorporate into the barbed end while they dissociate from the pointed end, resulting in a "treadmilling" of F-actin and regulation of growth cone dynamics (Katoh et al. 1999; Mallavarapu and Mitchison 1999). This process is further modulated by myosin motors and/or other actin regulators (Ishikawa and Kohama 2007).

\section{Actin and Microtubules Act in Parallel to Reinforce Neuronal Asymmetry}

Rearrangements of the actin cytoskeleton and microtubules are crucial for the initial establishment of polarity (Fig. 3). Before morphological polarization occurs, the future axon shows enhanced growth cone dynamics and, thereby, actin turnover (Bradke and Dotti 1999; Witte and Bradke 2008). By contrast, future dendrites, which are not growing at that stage, have a static growth cone with a rigid actin cytoskeleton. Pharmacological depolymerization of the actin cytoskeleton transforms nongrowing dendrites into growing axons (Bradke and Dotti 1999; Bradke and Dotti 2000; Kunda et al. 2001; Schwamborn and Puschel 2004). This suggests that the actin filaments of future dendritic growth cones form a barrier for the protrusion of microtubules, whereas the axonal growth cone contains an actin structure permissive for microtubule protrusion (Forscher and Smith 1988). Microtubules are also actively involved in neuronal polarization (Witte and Bradke 2008). Axonal microtubules are more stable in comparison to minor neurites and pharmacological stabilization of microtubules is sufficient to induce axon formation (Witte et al. 2008). As actin dynamics and microtubule stability are regulated through various cytoskeletal effectors, a plethora of signaling mechanisms influence axon growth.

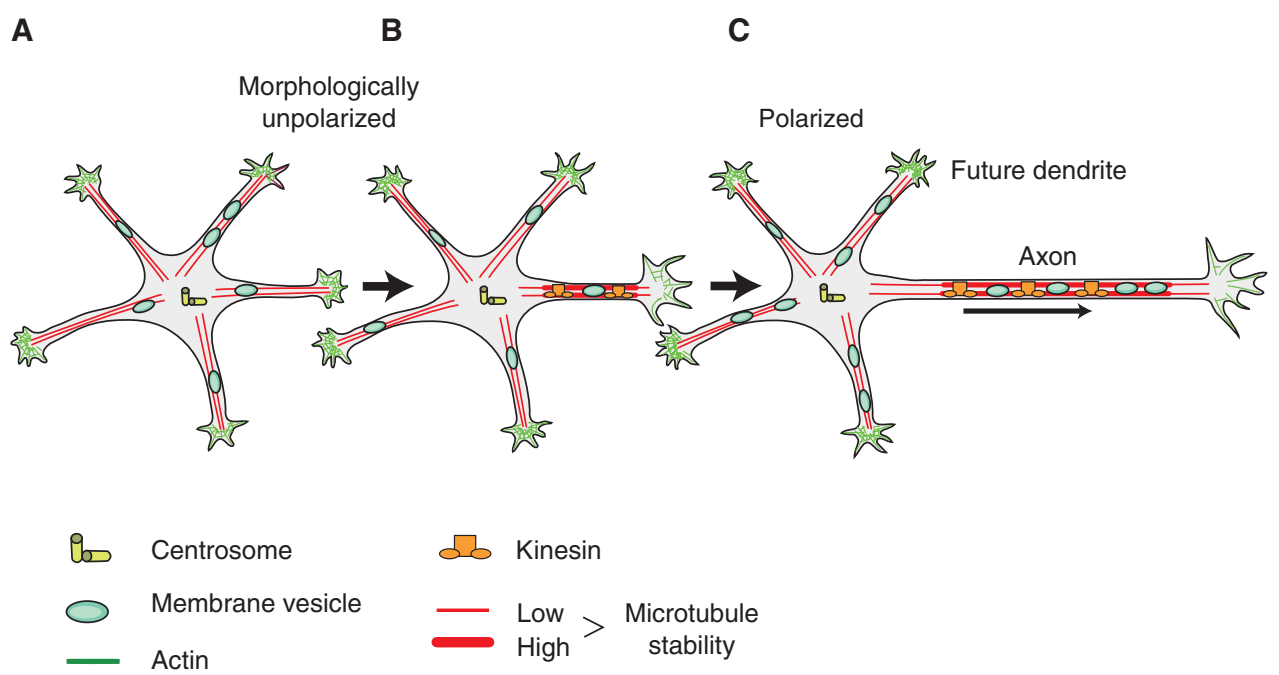

Figure 3. Intracellular mechanisms driving neuronal polarization. Morphologically unpolarized neurons bear several equal neuronal processes. $(A)$ In one of these processes, intracellular signaling pathways, leading to axon formation, are activated and result in early changes in cytoskeleton dynamics. (B) This neurite starts elongating rapidly and a morphologically polarized neuron bearing an axon is formed. $(C)$ The intracellular symmetry-breaking events are represented schematically: (1) centrosome (yellow) as the potential spatial signal for axon initiation; (2) cytoskeletal changes: the actin cytoskeleton (green) in the axonal growth cone is more dynamic and microtubules (red) are more stable in comparison to minor neurites; (3) stable microtubules are recognized by particular kinesin motors (orange) that induce unidirectional membrane trafficking (green) toward the axon. This leads to molecular segregation of cellular components and neuronal polarization. Reprinted, with permission from Witte and Bradke 2008. 
Actin Regulating Proteins and Their Relevance in Neuronal Polarity

Actin dynamics are regulated by actin nucleating, severing, branching, and bundling proteins. Branched actin filaments in lamellipodia are likely nucleated by the Arp $2 / 3$ complex (Ishikawa and Kohama 2007), whereas formins appear as actin nucleators in filopodia (Faix and Rottner 2006; Kovar 2006). However, these views have been challenged by other studies that suggest that Arp2/3 is also important for filopodia formation (Korobova and Svitkina 2008) or dispensable for actin organization in neuronal growth cones (Strasser et al. 2004).

Beside actin nucleators, other regulators of growth cone dynamics include proteins that directly modulate actin dynamics including WAVE (Wiskott-Aldrich syndrome protein [WASP]-family verprolin-homologous protein), Ena (enabled)/VASP (vasodilator stimulated phosphoprotein), profilin, and ADF (actin depolymerizing factor)/cofilin (Ishikawa and Kohama 2007). WAVE is localized to lamellipodia and is part of the WAVE-complex of proteins that act together to regulate actin polymerization in lamellipodia (Takenawa and Miki 2001; Takenawa and Suetsugu 2007). The WAVE pathway regulates actin polymerization through Arp2/3 (Takenawa and Miki 2001) or profilin II (Pilo Boyl et al. 2007) and promotes axon growth (Bogdan et al. 2004; Kawano et al. 2005). A mouse knockout of the WAVEcomplex component Nap1 (Nck-associated protein 1) shows defects in cortical neuronal differentiation, including reduced axon extension (Yokota et al. 2007).

The Ena/VASP proteins, localized to tips of lamellipodia and filopodia, accelerate actin polymerization by their anticapping activity and bundle actin filaments (Krause et al. 2003; Kwiatkowski et al. 2003). Indeed, deletion of all three mammalian Ena/VASP proteins causes aberrant actin bundling and failure of filopodia formation (Kwiatkowski et al. 2007). Importantly, neurons lacking these proteins fail to form neurites. The role of Ena/VASP signaling in axon formation appears to be conserved throughout species (Krause et al. 2004; Adler et al. 2006). Additionally, Ena/VASP proteins recruit the actin regulator profilin, but the physiological relevance of this interaction is still not clear (Krause et al. 2003). Profilin localizes to the leading edges of growth cones and enhances the formation of ATP-bound G-actin monomers that are incorporated into actin barbed-ends (Kwiatkowski et al. 2003). The ablation of the neuronal isoform profilin IIa results in destabilization of the actin cytoskeleton and increased neurite length and number (Da Silva et al. 2003). Surprisingly, profilin II-knockout mice polarize normally, suggesting that profilin I may compensate for profilin II. Profilin I-knockout mice are embryonically lethal (Witke et al. 2001) and future analysis of conditional knockout mice will help to reveal its role in neuronal development.

Actin severing proteins, including cofilin, are also implicated in neuronal polarity (Sarmiere and Bamburg 2004). Two of the three mammalian cofilins, ADF and cofilin I (nonmuscle (N)-cofilin), are expressed in the brain. $\mathrm{ADF}$ and cofilin are abundant in neuronal growth cones. They bind with higher activity to ADP-actin than to ATP-actin, resulting in their association with the pointed end of actin filaments and promoting actin depolymerization (Pak et al. 2008). ADF and cofilin are regulated by phosphorylation and the phosphorylated (nonactive) form is the most abundant cellular form. Cofilin is highly active in the axonal growth cones compared to nongrowing future dendritic growth cones. Moreover, knocking down cofilin interferes with axon formation, whereas expression of a constitutively active cofilin mutant leads to growth enhancement (Garvalov et al. 2007; Jacobs et al. 2007). Together, actin regulating proteins modulate the actin cytoskeleton to implement neuronal symmetry breakage. Interestingly, we still understand very little about which structural aspect of the actin cytoskeleton is determinant for neuronal polarization.

\section{Microtubule Regulating Proteins in Neuronal Polarity}

Microtubules are dynamically unstable polymers that undergo alternating phases of 
growth and shrinkage, known as "rescue" and "catastrophe," respectively. Microtubule stability is regulated via microtubule-associated proteins (MAPs). Some MAPs, such as MAP1B or MAP2, are of particular interest for neuronal polarity because of their ability to interact with both actin and microtubules.

To MAPs belong plus-end tracking proteins (+TIPs) and structural proteins, including the MAP2/Tau family of proteins (Dehmelt and Halpain 2004). + TIPs, such as cytoplasmic linker proteins (CLIPs) and CLIP-associated proteins (CLASPs) accumulate at growing microtubule plus ends and regulate microtubule dynamics (Galjart 2005). CLIPs and CLASPs act as microtubule growth-promoting factors and as microtubule stabilizing proteins, respectively (Galjart 2005). Their role in neuronal polarity remains to be investigated. Structural MAPs, such as MAP2/Tau, are highly expressed in the nervous system and regulate neurite formation (Dehmelt and Halpain 2004). MAP2 and Tau act as microtubule stabilizing proteins and are able to reduce "catastrophe" and promote rescue events of microtubule growth (Dehmelt and Halpain 2004). Down-regulation of MAP2 inhibits neurite formation, whereas down-regulation of Tau inhibits axon formation (Caceres and Kosik 1990; Caceres et al. 1992). However, knockout mouse models of these molecules have no neuronal polarity defects (Dehmelt and Halpain 2004; Dehmelt and Halpain 2005), suggesting functional redundancy with other MAPs (DiTella et al. 1996). Microtubule destabilizing proteins such as Op18/Stathmin may also influence neuronal polarity (Morii et al. 2006; Watabe-Uchida et al. 2006). Inactivation of Stathmin/Op18 by phosphorylation promotes microtubule stability and is necessary for the specification of the nascent axon.

Although most MAPs enhance microtubule stability by direct binding to the microtubule polymers, collapsin response mediator protein-2 (CRMP-2) binds to free tubulin subunits and promotes their capacity to bind to microtubules (Fukata et al. 2002). During neuronal differentiation, CRMP-2 accumulates in one neurite, the future axon, before morphological polarization occurs. When overexpressed in hippocampal neurons, it induces formation of multiple axons (Inagaki et al. 2001). Interestingly, CRMP-2 also regulates the kinesin-mediated transport of the WAVEcomplex into the axon and thereby promotes actin nucleation as well as axon growth and specification (Kawano et al. 2005).

In summary, microtubule regulating proteins have the potential to govern neuronal polarization by changing microtubule dynamics. However, whether microtubule regulating proteins directly affect neuronal polarity in vivo has not been documented so far.

Actin- and Microtubule-based Intracellular Transport is Required for Neuronal Polarity

Specific molecular motors move unidirectionally along actin filaments and microtubules (Ross et al. 2008) and regulate intracellular trafficking and thereby influence neuronal polarity. Most actin-directed motors, i.e., myosins, move towards actin barbed ends (Ikebe 2008). Disrupting myosin II reduces the "aretrograde flow" of actin and results in filopodia elongation (Ishikawa and Kohama 2007). Furthermore, depletion of myosin IIB results in an increased neurite outgrowth (Kollins et al. 2009).

The polarized stability of the microtubules may dictate axonal trafficking. The microtubule directed motors, kinesins and dyneins, are mostly plus-end and minus-end directed, respectively (Fig. 2A) (Goldstein and Yang 2000). Posttranslational modifications of microtubules can regulate the binding affinities of kinesin motors (Westermann and Weber 2003). For example, the axonal kinesin-1 transports cargo preferentially along acetylated microtubules (Nakata and Hirokawa 2003; Reed et al. 2006). Consistently, the motor domain of kinesin-1, when overexpressed, accumulates in the future axon (Jacobson et al. 2006), the process with more acetylated microtubules (Witte et al. 2008). Another kinesin, KIF3A, also accumulates in the axon and may be required for axonal localization of Par3-aPKC complex and the establishment of neuronal polarity 
(Nishimura et al. 2004; Shi et al. 2004). Furthermore, before the axon forms, a bulk transport of membrane organelles enriches trans-Golgi-derived vesicles, mitochondria, peroxisomes, and ribosomes in the future axon (Fig. 3) (Bradke and Dotti 1997). These experiments support the importance of intracellular trafficking for the establishment of neuronal asymmetry.

\section{SIGNALING PATHWAYS REGULATING NEURONAL POLARIZATION}

In the following section, we describe how different signaling pathways act on the breakage of neuronal symmetry. It is noteworthy that, despite the wealth of different signaling mechanisms involved in neuronal polarization, they appear to converge on the cytoskeletal level.

\section{Lipid Signaling in Neuronal Polarity}

Specific lipids serve as identity tags and define different cellular membranes (see also McCaffrey and Macara 2009). Their asymmetric distribution spatially restricts signaling complexes to particular membrane domains. The plasma membrane ganglioside sialidase (PMGS), which hydrolyzes gangliosides, is a very early marker of neuronal polarity ( $\mathrm{Da}$ Silva et al. 2005). It is enriched in the neurite that will become an axon and signals to the actin cytoskeleton. The PMGS seems to be essential for axon formation since its depletion results in axon inhibition, whereas its increased activity accelerates neuronal polarization (Da Silva et al. 2005). PMGS activity localizes TrkA, a nerve growth factor (NGF) receptor, in one neurite, thereby spatially restricting phosphatidylinositol-3-kinase (PI3K) signaling and Rho activation. This enables triggering of axon inducing signals in a single neurite. This study is a rare example of an attempt to understand how an extracellular signal (NGF) induces intracellular changes to orchestrate neuronal polarity.

A signaling lipid that appears essential for polarity in many cell types, including neurons, is the phosphatidylinositol-3-phosphate $\left(\mathrm{PIP}_{3}\right)$, synthesized by PI3K (Arimura and
Kaibuchi 2005). PI3K is placed upstream of various regulators of both actin and microtubule dynamics (Fig. 4). PI3K localizes to the tip of the stage 3 axon and inhibition of this lipid kinase leads to the inhibition of axon formation in cultured hippocampal neurons (Shi et al. 2003). However, the relevance of PI3K signaling in axon formation in vivo is still unclear. PI3K-deficient mice show axon formation defects only in myelinated axons in the cerebral cortex and striatum, whereas hippocampal axons appear normal (Tohda et al. 2006).

\section{Glycogen Synthase Kinase (GSK)-3 $\beta$ \\ Signaling in Neuronal Polarity}

GSK-3 $\beta$ is one of the downstream effectors of PI3K signaling and has therefore also been linked to polarity in many cell types, including neurons (Jiang et al. 2005; Zhou and Snider 2005; Yoshimura et al. 2006). Specific localization of $\mathrm{PIP}_{3}$ in the axon acts as a scaffold to recruit other signaling molecules (Fig. 4). The Akt kinase directly binds to $\mathrm{PIP}_{3}$ and is subsequently recruited to the axon where it phosphorylates (inactivates) GSK-3 $\beta$ (Yoshimura et al. 2006). This allows a differential distribution of active GSK-3 $\beta$ in axons and dendrites. Consistent with this idea, increasing the activity of GSK-3 $\beta$ results in the inhibition of axon formation, whereas reducing its activity causes multiple axons (Jiang et al. 2005). GSK-3 $\beta$ phosphorylates (inactivates) CRMP-2, which in its active form regulates axon formation by promoting microtubule assembly, modulating actin dynamics and regulating the endocytosis of the cell adhesion molecule L1 (Nishimura et al. 2003; Arimura et al. 2004; Yoshimura et al. 2005). However, GSK-3 $\beta$ knockout neurons polarize normally, which might be because of the compensation by GSK-3 $\alpha$ (Kim et al. 2006).

\section{PAR Proteins in Neuronal Polarity}

The role of partitioning defective (PAR) complex proteins Par3, Par6, and atypical protein kinase $\mathrm{C}(\mathrm{aPKC})$ in regulating asymmetric cell division 


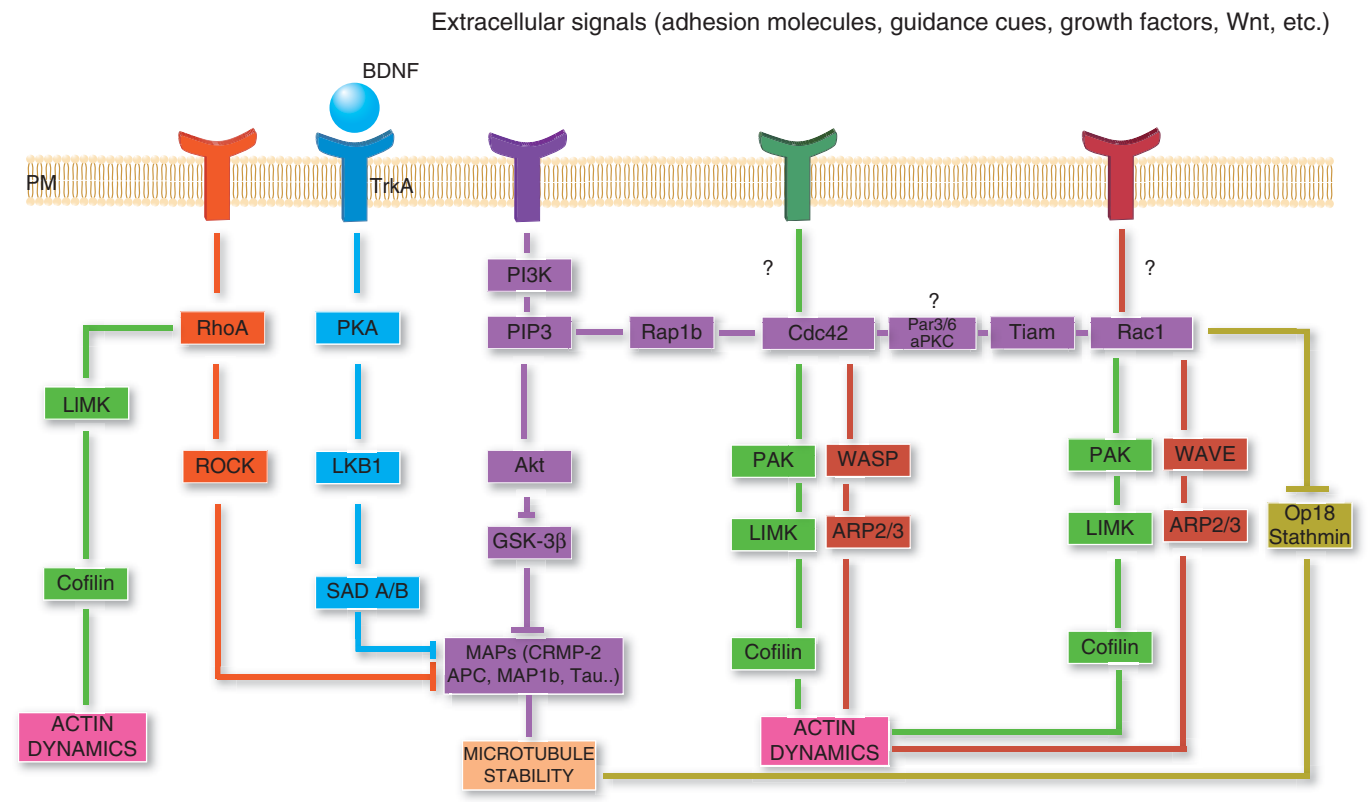

Figure 4. Coordination of extracellular and intracellular signaling regulates cytoskeletal dynamics and axon formation. Overview of selected signaling pathways that may initiate neuronal polarization and axon specification. BDNF signaling (blue) leads to activation of $\mathrm{PKA} / \mathrm{LKB} 1 / \mathrm{SAD} \mathrm{A} / \mathrm{B}$ signaling that regulates the stability of microtubules and induces axon formation. The PI3K/PIP $3 / A k t / G S K-3 \beta$ pathway (purple) regulates MAPs and the stability of microtubules. Another signaling branch activates Rap1B and the Rho GTPases Cdc42 and Rac1. Signals from both of these GTPases regulate actin dynamics via WASP/WAVE (red) or PAK-cofilin pathways (green). Racl may also regulate microtubules by regulating the microtubule destabilizer Op18/Stathmin. Apart from being downstream of PI3K signaling, Cdc42 and Rac1 may be activated by other signals (potential green and red plasma membrane $[\mathrm{PM}]$ receptors). Another molecule implicated in axon development is RhoA, which might regulate actin via the LIMK/cofilin pathway (green) or microtubule dynamics via ROCK signaling to MAPs (orange).

and inducing polarity has been described in many cellular systems, including Caenorhabditiis elegans, Drosophila, and mammals (Ohno 2001; Macara 2004; Goldstein and Macara 2007; see also McCaffrey and Macara 2009; Prehoda 2009). In vitro experiments suggest that the Par complex may also be required for axon development in mammalian neurons, downstream of PI3K (Fig. 4) (Shi et al. 2003; Macara 2004; Nishimura et al. 2004). However, in Drosophila, the Par complex is dispensable for axon-dendrite specification (Rolls and Doe 2004).

Other PARs, including PAR4 (LKB1) and the PAR-1 homolog synapses of amphids defective (SAD) kinases A and B have a clear role in neuronal polarity in vivo (Asada et al. 2007; Barnes et al. 2007; Shelly et al. 2007). LKB1 phosphorylates and activates SAD kinases that are responsible for development of polarity in cortical neurons. Although some PAR proteins have a conserved function during polarity processes throughout species, for other PAR proteins, a role within neuronal symmetry breakage remains to be shown.

\section{Rho GTPases in Neuronal Polarity}

Rho proteins, key regulators of the cellular cytoskeleton, have been implicated in a plethora of cellular processes, including the regulation of polarity, differentiation, cell adhesion and migration, cell cycle regulation, gene expression, and vesicle trafficking (EtienneManneville and Hall 2002; see also McCaffrey and Macara 2009). Main members of the 
Rho GTPase family comprise Cdc42 and Rac, and Rho GTPases are regulated through cycling between an inactive GDP-bound form and an active GTP-bound form (Jaffe and Hall 2005). These conversions are regulated by additional regulatory proteins, including guanine nucleotide-exchange factors (GEFs), GTPase activating proteins (GAPs), and guanine nucleotide-dissociation inhibitors (GDIs).

The Rho GTPase Cdc42 regulates actin dynamics, in particular filopodia formation and growth cone morphology (Govek et al. 2005). The major Cdc42 effectors in regulating actin dynamics are WASP and p21-activated kinase (PAK). The PAK pathway signals to the actin cytoskeleton via cofilin ( $\mathrm{Ng}$ and Luo 2004). Hippocampal Cdc42-knockout neurons have defects in their actin cytoskeleton, fail to form filopodia, and lack axons (Garvalov et al. 2007). Also, cofilin regulates axon formation downstream of $\mathrm{Cdc} 42$. Interestingly, the role of Cdc42-cofilin signaling in the establishment of neuronal polarity is conserved in invertebrates ( $\mathrm{Ng}$ and Luo 2004).

The small GTPase Racl is another polarity regulator (Govek et al. 2005). Rac1 modulates actin cytoskeleton dynamics by controlling the formation of lamellipodia (Hall 1998; Ridley 2001). The two main effector pathways regulating actin dynamics downstream of Racl are PAK and WAVE (Burridge and Wennerberg 2004; Stradal et al. 2004; Heasman and Ridley 2008). In addition, Rac acts on microtubule dynamics by inhibiting the microtubule destabilizer Stathmin/Op18 (Wittmann et al. 2004; Watabe-Uchida et al. 2006).

Experiments in cultured neurons have anticipated Racl as a positive regulator of axon growth (Govek et al. 2005; Koh 2006). However, specific ablation of Racl from the cortex does not influence axon growth, but rather axon guidance (Chen et al. 2007; Kassai et al. 2008). This may indicate that, in contrast to Drosophila neurons (Hakeda-Suzuki et al. 2002; Ng et al. 2002), mammalian neurons regulate axon growth independently of Racl. It is also feasible that Rac3 compensates for the role of Racl in polarity. Rac3 is a close homolog of Racl and is also expressed in the nervous system (Bolis et al. 2003). Examining neuronal polarity and axon development in the absence of both Rac isoforms is needed to clarify the role of these proteins in polarity.

Rho proteins comprise three isoforms: RhoA, RhoB, and RhoC. Knockout mice for RhoB and RhoC seem not to have major developmental defects (Liu et al. 2001; Hakem et al. 2005). The role of RhoA in neuronal development is anticipated from in vitro studies, but no RhoA-knockout mice have been described so far (Heasman and Ridley 2008). However, overexpression of RhoA mutant proteins negatively regulates neurite outgrowth (Koh 2006). Interestingly, modulating RhoA signaling may induce axon regeneration in the CNS after injury (Niederost et al. 2002; Hiraga et al. 2006; McKerracher and Higuchi 2006; Moore et al. 2008). RhoA and its effector Rho-kinase (ROCK) seem to have a critical role in axon growth and actin dynamics during neuritogenesis of cultured cerebellar granule neurons (Bito et al. 2000). Furthermore, the RhoA/ROCK pathway and profilin II regulate actin stability in cultured hippocampal neurons (Da Silva et al. 2003). RhoA/ROCK signaling has also been implicated in the regulation of microtubule stability (Arimura and Kaibuchi 2007). Future analysis of RhoA-knockout mice will reveal the physiological function of RhoA and its effectors during axon growth.

Taken together, whereas many signaling pathways have been implicated in the breakage of neuronal polarity, in many instances, their physiological relevance has not been shown. Most of the in vitro studies used dominantnegative and constitutively active mutants, which can exhibit nonspecific or nonphysiological effects resulting from perturbation of multiple signaling pathways (Wang and Zheng 2007). Therefore, the future challenge is to reveal which of the signaling pathways are regulating neuronal symmetry breakage in vivo.

\section{INTRINSIC MECHANISMS THAT GOVERN NEURONAL SYMMETRY BREAKING}

Although asymmetry in neurons arises through changes in the cytoskeleton, it is not clear how 
these changes are induced in the first place. What is the initial symmetry breaking event? How does a cell with undifferentiated neurites transform into a polarized cell bearing a single axon and several dendrites? It is assumed that positive and negative feedback loops regulate the breakage of neuronal symmetry in the absence of extrinsic cues (Goslin and Banker 1989; Andersen and Bi 2000). Mathematical modeling showed that a positive feedback alone may be sufficient to induce symmetry breakage (Altschuler et al. 2008). An increased local concentration of signaling molecules, such as Cdc42, Rac, or Par proteins, in specific regions of the plasma membrane, may trigger the recruitment of other signaling molecules, which then together direct the symmetry breakage (Butty et al. 2002; Shi et al. 2003; Gassama-Diagne et al. 2006).

The positive feedback loop model has been experimentally tested in budding yeast (Wedlich-Soldner et al. 2003; Altschuler et al. 2008). It has been shown that spontaneous polarization of $\mathrm{Cdc} 42$ at the cortical plasma membrane serves as an initial signal for symmetry breaking that may activate further downstream signals regulating the establishment and maintenance of cell polarity. Furthermore, in neurons, local Ras and PI3K positive feedback, localized activation of PI3K, or selective axonal transport of Par complex are some examples of positive feedback loops that may underlie symmetry breakage and axon formation (Nishimura et al. 2004; Shi et al. 2004; Toriyama et al. 2006; Fivaz et al. 2008)

It is likely that positive and negative regulatory circuits influence microtubule stability and actin dynamics in the future axon and therefore manifest polarity after an initial break of symmetry. Another possibility is that the position of the centrosome, as the major microtubule organizing center, dictates the site of axon formation (Higginbotham and Gleeson 2007; Bornens 2008). Consistent with this idea, after the last round of cell division, the centrosome of hippocampal neurons moves to the opposite pole of the last cleavage furrow. Axon formation then takes place from this site at later stages (de Anda et al. 2005). Moreover, experiments in cerebellar granule neurons showed that the centrosome localizes to the site where the initial axon is formed and that it later relocates to the place from where the second axon emerges (Zmuda and Rivas 1998).

However, other studies question the instructive role of the centrosome in axon formation. For example, Drosophila neurons devoid of functional centrosomes form and elongate their axons normally (Basto et al. 2006). Moreover, zebrafish retinal ganglion cells do not localize their centrosome to the site of axon formation (Zolessi et al. 2006). Future experiments will help to elucidate whether centrosome positioning gives the first spatial cue to break the symmetry, or simply is an epiphenomenon (Etienne-Manneville and Hall 2003; Siegrist and Doe 2007).

After discussing the intrinsic mechanisms regulating neuronal symmetry breaking, we now focus on extrinsic cues and their role in symmetry breaking, in particular, in vivo.

\section{EXTERNAL CUES INITIATING NEURONAL POLARIZATION}

Hippocampal neurons polarize in vitro when separated from extracellular cues (Craig and Banker 1994), arguing that the initial signal for breaking the neuronal symmetry is an intrinsic property of these neurons. However, studies have shown that extracellular cues can modulate polarization. This is certainly important in vivo, where neurons encounter an array of extracellular cues (Arimura and Kaibuchi 2007).

Experiments in cultured cells suggest that extracellular matrix and cell adhesion molecules influence elongation (Esch et al. 1999; Menager et al. 2004). Additionally, growth factors and integrins have been implicated as extracellular signals relevant for axon-dendrite specification in hippocampal neurons (Guo et al. 2007). Netrin and neurotrophins have also been proposed as extracellular regulators of axon specification and growth (Da Silva et al. 2005; Moore et al. 2008). In C. elegans, the nematode netrin homolog Unc-6 induces neuronal polarization 
and gives spatial information for axon formation (Adler et al. 2006). Another guidance cue, semaphorin (Sema) 3A, regulates asymmetric growth of cortical neurons by acting as repellant for axons and as chemoattractant for apical dendrites (Whitford et al. 2002). The Wnt pathway also induces neuronal polarity and axon outgrowth (Hilliard and Bargmann 2006; Prasad and Clark 2006). Moreover, two elegant studies in cortical neurons outlined a possible regulatory pathway starting from an extracellular signal, brain-derived neurotrophic factor (BDNF), down to the putative regulators of microtubule dynamics and axon formation (Fig. 4) (Shelly et al. 2007; Barnes et al. 2008). In short, BDNF binds to its receptor TrkA; this induces activation of a cAMP-dependent protein kinase A (PKA) that phosphorylates a serine/threonine kinase LKB1 (ortholog of C.elegans Par4), which in turn activates SAD kinases, negative regulators of MAPs (regulation of microtubule stability).

Taken together, the regulation of axondendrite polarity in vivo is induced or modulated by extracellular signals. These signals trigger intracellular events leading to changes in the cytoskeleton and the establishment of polarity.

\section{MAINTENANCE OF NEURONAL POLARITY}

After the initial establishment of neuronal polarity, neurons have to maintain their polarization to stably integrate into neuronal circuits. After dendritic maturation and synapse formation, axonal and dendritic membrane proteins segregate into different compartments (Jareb and Banker 1998; Ledesma et al. 1999; Dotti and Poo 2003). The segregation of axonal and dendritic proteins is achieved by active protein sorting at the trans-Golgi network into different vesicles, which are then transported into axons or dendrites. The question is which mechanisms are important for the maintenance of the molecular segregation of axonal and dendritic proteins. A physical barrier that exists at the axonal initial segment is an important mechanism for the maintenance of molecular segregation of both membrane and cytoplasmic proteins (Nakada et al. 2003; Song et al. 2009). An additional mechanism contributing to the maintenance of asymmetric distribution of signaling molecules in neurons might be the regulation of protein stability. Restriction of Akt protein kinase or GTPase Rap1B to the axon results from selective degradation of this protein in dendrites, mediated by the classical ubiquitin-proteosome system. Inhibition of this mechanism causes a symmetric distribution of these molecules to all processes and induction of multiple axons (Yan et al. 2006; Schwamborn et al. 2007).

\section{REBREAKING NEURONAL SYMMETRY}

An interesting question in neuronal polarity is how reversible this process is. Young (Dotti and Banker 1987; Goslin and Banker 1989; Bradke and Dotti 2000; Takahashi et al. 2007), functionally polarized (Gomis-Ruth et al. 2008), and, likely, adult neurons (Havton and Kellerth 1987; Fenrich et al. 2007) can transform a dendrite into an axon, after cutting the original axon close to the cell body. This demonstrates a high degree of neuronal plasticity, even after neurons have polarized and integrated into a neuronal network. On the other hand, if the axon is cut more distally, the original axon regrows, indicating that the distal axon contains a specific landmark that manifests axonal identity.

Our knowledge about the underlying molecular mechanisms that enable dendriticaxonal transformation remains fragmentary, but stable microtubules provide one cue of axonal identity (Gomis-Ruth et al. 2008; Sweet and Firestein 2008; Witte and Bradke 2008). Importantly, stabilizing microtubules after axonal injury results in reduced axonal degeneration in vivo and axonal regrowth in cultured neurons (Erturk et al. 2007). One can envision that axon regeneration could be triggered in the lesioned CNS by inducing repolarization of the injured axons. Hence, microtubule stabilization at the injury site may lead to axon regeneration and may have some clinical relevance for treating spinal cord injury. 


\section{CONCLUDING REMARKS}

Neurons break their symmetry through different extrinsic and intrinsic signaling pathways that converge on the regulation of actin and microtubule dynamics. These cytoskeletal components underlie the polarization of neurons as axon formation is governed by dynamic instability of actin and stabilization of microtubules. Our understanding of the intracellular mechanisms and molecular players regulating neuronal polarization provides a solid platform to address the following major issues in the field: First, we still know relatively little about which of the proposed polarity signals are relevant under physiological conditions and how these different signaling pathways interact with each other to bring about neuronal polarization. Second, we need to explore extracellular signaling in more detail to better understand how these signals propagate within the cell and regulate neuronal polarity. And third, we know relatively little about how actin and microtubules interact with each other to bring about neuronal polarization. Our understanding of the molecular mechanisms leading to neuronal polarization may also help to manipulate injured CNS neurons so that they regenerate their axon upon stimulating their re-polarization.

\section{ACKNOWLEDGMENTS}

We are indebted to Robert Schorner for help with the preparation of figures. We thank Claudia Laskowski, Dorothee Neukirchen, Kevin Flynn, and Michael Stieb for critically reading the manuscript. We are grateful to Dorothee Neukirchen, Kevin Flynn, and Michael Stieb for the images of hippocampal neurons. This work was supported by the Max Planck Society and the DFG. F.B. is a recipient of a Career Development Award from the Human Frontier Science Program.

\section{REFERENCES}

Adler CE, Fetter RD, Bargmann CI. 2006. UNC-6/Netrin induces neuronal asymmetry and defines the site of axon formation. Nat Neurosci 9: 511-518.
Altschuler SJ, Angenent SB, Wang Y, Wu LF. 2008. On the spontaneous emergence of cell polarity. Nature 454: 886-889.

Andersen SS, Bi GQ. 2000. Axon formation: A molecular model for the generation of neuronal polarity. Bioessays 22: $172-9$.

Arimura N, Kaibuchi K. 2005. Key regulators in neuronal polarity. Neuron 48: $881-884$.

Arimura N, Kaibuchi K. 2007. Neuronal polarity: From extracellular signals to intracellular mechanisms. Nat Rev Neurosci 8: 194-205.

Arimura N, Menager C, Fukata Y, Kaibuchi K. 2004. Role of CRMP-2 in neuronal polarity. J Neurobiol 58: 34-47.

Asada N, Sanada K, Fukada Y. 2007. LKB1 regulates neuronal migration and neuronal differentiation in the developing neocortex through centrosomal positioning. J Neurosci 27: 11769-11775.

Barnes AP, Solecki D, Polleux F. 2008. New insights into the molecular mechanisms specifying neuronal polarity in vivo. Curr Opin Neurobiol 18: 44-52.

Barnes AP, Lilley BN, Pan YA, Plummer LJ, Powell AW, Raines AN, Sanes JR, Polleux F. 2007. LKB1 and SAD kinases define a pathway required for the polarization of cortical neurons. Cell 129: 549-563.

Basto R, Lau J, Vinogradova T, Gardiol A, Woods CG, Khodjakov A, Raff JW. 2006. Flies without centrioles. Cell 125: 86.

Bito H, Furuyashiki T, Ishihara H, Shibasaki Y, Ohashi K, Mizuno K, Maekawa M, Ishizaki T, Narumiya S. 2000. A critical role for a Rho-associated kinase, p160ROCK, in determining axon outgrowth in mammalian CNS neurons. Neuron 26: 431-441.

Bogdan S, Grewe O, Strunk M, Mertens A, Klambt C 2004. Sra-1 interacts with Kette and Wasp and is required for neuronal and bristle development in Drosophila. Development 131: 3981-3989.

Bolis A, Corbetta S, Cioce A, de Curtis I. 2003. Differential distribution of Rac1 and Rac3 GTPases in the developing mouse brain: Implications for a role of Rac3 in Purkinje cell differentiation. Eur J Neurosci 18: 2417-2424.

Bornens M. 2008. Organelle positioning and cell polarity. Nat Rev Mol Cell Biol 9: 874-886.

Bradke F, Dotti CG. 1997. Neuronal polarity: Vectorial cytoplasmic flow precedes axon formation. Neuron 19: 1175-1186.

Bradke F, Dotti CG. 1999. The role of local actin instability in axon formation. Science 283: 1931-1934.

Bradke F, Dotti CG. 2000. Differentiated neurons retain the capacity to generate axons from dendrites. Curr Biol 10: $1467-1470$.

Burridge K, Wennerberg K. 2004. Rho and Rac take center stage. Cell 116: 167-179.

Butty AC, Perrinjaquet N, Petit A, Jaquenoud M, Segall JE, Hofmann K, Zwahlen C, Peter M. 2002. A positive feedback loop stabilizes the guanine-nucleotide exchange factor Cdc24 at sites of polarization. Embo $J$ 21: 1565-1576.

Caceres A, Kosik KS. 1990. Inhibition of neurite polarity by tau antisense oligonucleotides in primary cerebellar neurons. Nature 343: 461-463. 
S. Tahirovic and F. Bradke

Caceres A, Mautino J, Kosik KS. 1992. Suppression of MAP2 in cultured cerebellar macroneurons inhibits minor neurite formation. Neuron 9: 607-618.

Chen L, Liao G, Waclaw RR, Burns KA, Linquist D, Campbell K, Zheng Y, Kuan CY. 2007. Racl controls the formation of midline commissures and the competency of tangential migration in ventral telencephalic neurons. J Neurosci 27: 3884-3893.

Craig AM, Banker G. 1994. Neuronal polarity. Annu Rev Neurosci 17: 267-310.

Da Silva JS, Hasegawa T, Miyagi T, Dotti CG, AbadRodriguez J. 2005. Asymmetric membrane ganglioside sialidase activity specifies axonal fate. Nat Neurosci 8: 606-615.

Da Silva JS, Medina M, Zuliani C, Di Nardo A, Witke W, Dotti CG. 2003. RhoA/ROCK regulation of neuritogenesis via profilin IIa-mediated control of actin stability. J Cell Biol 162: 1267-1279.

de Anda FC, Pollarolo G, Da Silva JS, Camoletto PG, Feiguin F, Dotti CG. 2005. Centrosome localization determines neuronal polarity. Nature 436: 704-708.

Dehmelt L, Halpain S. 2004. Actin and microtubules in neurite initiation: Are MAPs the missing link? J Neurobiol 58: 18-33.

Dehmelt L, Halpain S. 2005. The MAP2/Tau family of microtubule-associated proteins. Genome Biol 6: 204.

Dickson BJ. 2002. Molecular mechanisms of axon guidance. Science 298: 1959-1964.

DiTella MC, Feiguin F, Carri N, Kosik KS, Caceres A. 1996. MAP-1B/TAU functional redundancy during lamininenhanced axonal growth. J Cell Sci 109: 467-477.

Dotti CG, Banker GA. 1987. Experimentally induced alteration in the polarity of developing neurons. Nature 330: 254-256.

Dotti CG, Poo MM. 2003. Neuronal polarization: Building fences for molecular segregation. Nat Cell Biol 5: $591-594$.

Dotti CG, Sullivan CA, Banker GA. 1988. The establishment of polarity by hippocampal neurons in culture. J Neurosci 8: $1454-1468$.

Erturk A, Hellal F, Enes J, Bradke F. 2007. Disorganized microtubules underlie the formation of retraction bulbs and the failure of axonal regeneration. J Neurosci 27: 9169-9180.

Esch T, Lemmon V, Banker G. 1999. Local presentation of substrate molecules directs axon specification by cultured hippocampal neurons. J Neurosci 19: 6417-6426.

Etienne-Manneville S, Hall A. 2002. Rho GTPases in cell biology. Nature 420: 629-635.

Etienne-Manneville S, Hall A. 2003. Cdc42 regulates GSK-3 $\beta$ and adenomatous polyposis coli to control cell polarity. Nature 421: 753-756.

Faix J, Rottner K. 2006. The making of filopodia. Curr Opin Cell Biol 18: 18-25.

Fenrich KK, Skelton N, MacDermid VE, Meehan CF, Armstrong S, Neuber-Hess MS, Rose PK. 2007. Axonal regeneration and development of de novo axons from distal dendrites of adult feline commissural interneurons after a proximal axotomy. J Comp Neurol 502: 1079-1097.
Fivaz M, Bandara S, Inoue T, Meyer T. 2008. Robust neuronal symmetry breaking by Ras-triggered local positive feedback. Curr Biol 18: 44-50.

Forscher P, Smith SJ. 1988. Actions of cytochalasins on the organization of actin filaments and microtubules in a neuronal growth cone. J Cell Biol 107: 1505-1516.

Fukata Y, Itoh TJ, Kimura T, Menager C, Nishimura T, Shiromizu T, Watanabe $\mathrm{H}$, Inagaki $\mathrm{N}$, Iwamatsu $\mathrm{A}$, Hotani H, et al. 2002. CRMP-2 binds to tubulin heterodimers to promote microtubule assembly. Nat Cell Biol 4: 583-591.

Galjart N. 2005. CLIPs and CLASPs and cellular dynamics. Nat Rev Mol Cell Biol 6: 487-498.

Garvalov BK, Flynn KC, Neukirchen D, Meyn L, Teusch N, Wu X, Brakebusch C, Bamburg JR, Bradke F. 2007. $\mathrm{Cdc} 42$ regulates cofilin during the establishment of neuronal polarity. J Neurosci 27: 13117-13129.

Gassama-Diagne A, Yu W, ter Beest M, Martin-Belmonte F, Kierbel A, Engel J, Mostov K. 2006. Phosphatidylinositol3,4,5-trisphosphate regulates the formation of the basolateral plasma membrane in epithelial cells. Nat Cell Biol 8: 963-970.

Goldstein B, Macara IG. 2007. The PAR proteins: Fundamental players in animal cell polarization. Dev Cell 13: 609-622.

Goldstein LS, Yang Z. 2000. Microtubule-based transport systems in neurons: The roles of kinesins and dyneins. Annu Rev Neurosci 23: 39-71.

Gomis-Ruth S, Wierenga CJ, Bradke F. 2008. Plasticity of polarization: Changing dendrites into axons in neurons integrated in neuronal circuits. Curr Biol 18: 992-1000.

Goslin K, Banker G. 1989. Experimental observations on the development of polarity by hippocampal neurons in culture. J Cell Biol 108: 1507-1516.

Govek EE, Newey SE, Van Aelst L. 2005. The role of the Rho GTPases in neuronal development. Genes Dev 19: 1-49.

Guo W, Jiang H, Gray V, Dedhar S, Rao Y. 2007. Role of the integrin-linked kinase (ILK) in determining neuronal polarity. Dev Biol 306: 457-468.

Hakeda-Suzuki S, Ng J, Tzu J, Dietzl G, Sun Y, Harms M, Nardine T, Luo L, Dickson BJ. 2002. Rac function and regulation during Drosophila development. Nature 416: 438-442.

Hakem A, Sanchez-Sweatman O, You-Ten A, Duncan G, Wakeham A, Khokha R, Mak TW. 2005. RhoC is dispensable for embryogenesis and tumor initiation but essential for metastasis. Genes Dev 19: 1974-1979.

Hall A. 1998. Rho GTPases and the actin cytoskeleton. Science 279: 509-514.

Havton L, Kellerth JO. 1987. Regeneration by supernumerary axons with synaptic terminals in spinal motoneurons of cats. Nature 325: 711-714.

Heasman SJ, Ridley AJ. 2008. Mammalian Rho GTPases: New insights into their functions from in vivo studies. Nat Rev Mol Cell Biol 9: 690-701.

Higginbotham HR, Gleeson JG. 2007. The centrosome in neuronal development. Trends Neurosci 30: 276-283.

Hilliard MA, Bargmann CI. 2006. Wnt signals and frizzled activity orient anterior-posterior axon outgrowth in C. elegans. Dev Cell 10: 379-390. 
Hiraga A, Kuwabara S, Doya H, Kanai K, Fujitani M, Taniguchi J, Arai K, Mori M, Hattori T, Yamashita T. 2006. Rho-kinase inhibition enhances axonal regeneration after peripheral nerve injury. J Peripher Nerv Syst 11: $217-224$.

Ikebe M. 2008. Regulation of the function of mammalian myosin and its conformational change. Biochem Biophys Res Commun 369: 157-164.

Inagaki N, Chihara K, Arimura N, Menager C, Kawano Y, Matsuo N, Nishimura T, Amano M, Kaibuchi K. 2001. CRMP-2 induces axons in cultured hippocampal neurons. Nat Neurosci 4: 781-782.

Ishikawa R, Kohama K. 2007. Actin-binding proteins in nerve cell growth cones. J Pharmacol Sci 105: 6-11.

Jacobs T, Causeret F, Nishimura YV, Terao M, Norman A, Hoshino M, Nikolic M. 2007. Localized activation of p21-activated kinase controls neuronal polarity and morphology. J Neurosci 27: 8604-8615.

Jacobson C, Schnapp B, Banker GA. 2006. A change in the selective translocation of the Kinesin-1 motor domain marks the initial specification of the axon. Neuron 49: 797-804.

Jaffe AB, Hall A. 2005. Rho GTPases: Biochemistry and biology. Annu Rev Cell Dev Biol 21: 247-269.

Jareb M, Banker G. 1998. The polarized sorting of membrane proteins expressed in cultured hippocampal neurons using viral vectors. Neuron 20: 855-867.

Jiang H, Guo W, Liang X, Rao Y. 2005. Both the establishment and the maintenance of neuronal polarity require active mechanisms: Critical roles of GSK- $3 \beta$ and its upstream regulators. Cell 120: 123-135.

Kaech S, Banker G. 2006. Culturing hippocampal neurons. Nat Protoc 1: 2406-2415.

Kassai H, Terashima T, Fukaya M, Nakao K, Sakahara M, Watanabe M, Aiba A. 2008. Rac1 in cortical projection neurons is selectively required for midline crossing of commissural axonal formation. Eur J Neurosci 28: 257-267.

Katoh K, Hammar K, Smith PJ, Oldenbourg R. 1999. Birefringence imaging directly reveals architectural dynamics of filamentous actin in living growth cones. Mol Biol Cell 10: 197-210.

Kawano Y, Yoshimura T, Tsuboi D, Kawabata S, Kaneko-Kawano T, Shirataki H, Takenawa T, Kaibuchi K. 2005. CRMP-2 is involved in kinesin-1-dependent transport of the Sra-1/WAVE1 complex and axon formation. Mol Cell Biol 25: 9920-9935.

Kim WY, Zhou FQ, Zhou J, Yokota Y, Wang YM, Yoshimura T, Kaibuchi K, Woodgett JR, Anton ES, Snider WD. 2006. Essential roles for GSK-3s and GSK-3-primed substrates in neurotrophin-induced and hippocampal axon growth. Neuron 52: 981-996.

Koh CG. 2006. Rho GTPases and their regulators in neuronal functions and development. Neurosignals 15: $228-237$.

Kollins KM, Hu J, Bridgman PC, Huang YQ, Gallo G. 2009. Myosin-II negatively regulates minor process extension and the temporal development of neuronal polarity. Dev Neurobiol 69: 279-298.

Korobova F, Svitkina T. 2008. Arp2/3 complex is important for filopodia formation, growth cone motility, and neuritogenesis in neuronal cells. Mol Biol Cell 19: 1561-1574.

Kovar DR. 2006. Molecular details of formin-mediated actin assembly. Curr Opin Cell Biol 18: 11-17.

Krause M, Dent EW, Bear JE, Loureiro JJ, Gertler FB. 2003. Ena/VASP proteins: regulators of the actin cytoskeleton and cell migration. Annu Rev Cell Dev Biol 19: 541-564.

Krause M, Leslie JD, Stewart M, Lafuente EM, Valderrama F, Jagannathan R, Strasser GA, Rubinson DA, Liu H, Way $\mathrm{M}$, et al. 2004. Lamellipodin, an Ena/VASP ligand, is implicated in the regulation of lamellipodial dynamics. Dev Cell 7: 571-583.

Kunda P, Paglini G, Quiroga S, Kosik K, Caceres A. 2001. Evidence for the involvement of Tiam1 in axon formation. J Neurosci 21: 2361-2372.

Kwiatkowski AV, Gertler FB, Loureiro JJ. 2003. Function and regulation of Ena/VASP proteins. Trends Cell Biol 13: 386-392.

Kwiatkowski AV, Rubinson DA, Dent EW, Edward van Veen J, Leslie JD, Zhang J, Mebane LM, Philippar U, Pinheiro EM, Burds AA, et al. 2007. Ena/VASP Is Required for neuritogenesis in the developing cortex. Neuron 56: 441-455.

Ledesma MD, Brugger B, Bunning C, Wieland FT, Dotti CG. 1999. Maturation of the axonal plasma membrane requires upregulation of sphingomyelin synthesis and formation of protein-lipid complexes. Embo $J$ 18: 1761-1771.

Li R, Gundersen GG. 2008. Beyond polymer polarity: How the cytoskeleton builds a polarized cell. Nat Rev Mol Cell Biol 9: 860-73.

Liu AX, Rane N, Liu JP, Prendergast GC. 2001. RhoB is dispensable for mouse development, but it modifies susceptibility to tumor formation as well as cell adhesion and growth factor signaling in transformed cells. Mol Cell Biol 21: 6906-6912.

Macara IG. 2004. Parsing the polarity code. Nat Rev Mol Cell Biol 5: 220-31.

Mallavarapu A, Mitchison T. 1999. Regulated actin cytoskeleton assembly at filopodium tips controls their extension and retraction. J Cell Biol 146: 1097-1106.

McCaffrey LM, Macara IG. 2009. Widely conserved signaling pathways in the establishment of cell polarity. Cold Spring Harb Perspect Biol 1: a001370.

McKerracher L, Higuchi H. 2006. Targeting Rho to stimulate repair after spinal cord injury. J Neurotrauma 23: 309-317.

Menager C, Arimura N, Fukata Y, Kaibuchi K. 2004. PIP3 is involved in neuronal polarization and axon formation. $J$ Neurochem 89: 109-118.

Moore SW, Correia JP, Lai Wing Sun K, Pool M, Fournier AE, Kennedy TE. 2008. Rho inhibition recruits DCC to the neuronal plasma membrane and enhances axon chemoattraction to netrin 1. Development 135: 2855-2864.

Morii H, Shiraishi-Yamaguchi Y, Mori N. 2006. SCG10, a microtubule destabilizing factor, stimulates the neurite outgrowth by modulating microtubule dynamics in rat hippocampal primary cultured neurons. J Neurobiol 66: 1101-1114.

Nakada C, Ritchie K, Oba Y, Nakamura M, Hotta Y, Iino R, Kasai RS, Yamaguchi K, Fujiwara T, Kusumi A. 2003. 
S. Tahirovic and F. Bradke

Accumulation of anchored proteins forms membrane diffusion barriers during neuronal polarization. Nat Cell Biol 5: 626-632.

Nakata T, Hirokawa N. 2003. Microtubules provide directional cues for polarized axonal transport through interaction with kinesin motor head. J Cell Biol 162: 1045-1055.

Ng J, Luo L. 2004. Rho GTPases regulate axon growth through convergent and divergent signaling pathways. Neuron 44: 779-793.

Ng J, Nardine T, Harms M, Tzu J, Goldstein A, Sun Y, Dietzl G, Dickson BJ, Luo L. 2002. Rac GTPases control axon growth, guidance and branching. Nature 416: $442-447$.

Niederost B, Oertle T, Fritsche J, McKinney RA, Bandtlow CE. 2002. Nogo-A and myelin-associated glycoprotein mediate neurite growth inhibition by antagonistic regulation of RhoA and Racl. J Neurosci 22: 10368-10376.

Nishimura T, Fukata Y, Kato K, Yamaguchi T, Matsuura Y, Kamiguchi H, Kaibuchi K. 2003. CRMP-2 regulates polarized Numb-mediated endocytosis for axon growth. Nat Cell Biol 5: 819-826.

Nishimura T, Kato K, Yamaguchi T, Fukata Y, Ohno S, Kaibuchi K. 2004. Role of the PAR-3-KIF3 complex in the establishment of neuronal polarity. Nat Cell Biol 6: 328-334.

Ohno S. 2001. Intercellular junctions and cellular polarity: The PAR-aPKC complex, a conserved core cassette playing fundamental roles in cell polarity. Curr Opin Cell Biol 13: 641-648.

Pak CW, Flynn KC, Bamburg JR. 2008. Actin-binding proteins take the reins in growth cones. Nat Rev Neurosci 9: 136-147.

Pilo Boyl P, Di Nardo A, Mulle C, Sassoe-Pognetto M, Panzanelli P, Mele A, Kneussel M, Costantini V, Perlas E, Massimi M, et al. 2007. Profilin2 contributes to synaptic vesicle exocytosis, neuronal excitability, and noveltyseeking behavior. Embo J 26: 2991-3002.

Powell SK, Rivas RJ, Rodriguez-Boulan E, Hatten ME. 1997. Development of polarity in cerebellar granule neurons. J Neurobiol 32: 223-236.

Prasad BC, Clark SG. 2006. Wnt signaling establishes anteroposterior neuronal polarity and requires retromer in C. elegans. Development 133: 1757-1766.

Prehoda KE. 2009. Polarization of Drosophila neuroblasts during asymmetric division. Cold Spring Harb Perspect Biol 1: a001388.

Reed NA, Cai D, Blasius TL, Jih GT, Meyhofer E, Gaertig J, Verhey KJ. 2006. Microtubule acetylation promotes kinesin-1 binding and transport. Curr Biol 16: 2166-2172.

Ridley AJ. 2001. Rho GTPases and cell migration. J Cell Sci 114: $2713-2722$.

Rolls MM, Doe CQ. 2004. Baz, Par-6 and aPKC are not required for axon or dendrite specification in Drosophila. Nat Neurosci 7: 1293-1295.

Ross JL, Ali MY, Warshaw DM. 2008. Cargo transport: Molecular motors navigate a complex cytoskeleton. Curr Opin Cell Biol 20: 41-47.
Sarmiere PD, Bamburg JR. 2004. Regulation of the neuronal actin cytoskeleton by ADF/cofilin. J Neurobiol 58: 103-117.

Schwamborn JC, Puschel AW. 2004. The sequential activity of the GTPases Rap1B and Cdc42 determines neuronal polarity. Nat Neurosci 7: 923-929.

Schwamborn JC, Muller M, Becker AH, Puschel AW. 2007. Ubiquitination of the GTPase Rap1B by the ubiquitin ligase Smurf2 is required for the establishment of neuronal polarity. Embo J 26: 1410-1422.

Shelly M, Cancedda L, Heilshorn S, Sumbre G, Poo MM. 2007. LKB1/STRAD promotes axon initiation during neuronal polarization. Cell 129: 565-577.

Shi SH, Jan LY, Jan YN. 2003. Hippocampal neuronal polarity specified by spatially localized mPar3/mPar6 and PI 3-kinase activity. Cell 112: 63-75.

Shi SH, Cheng T, Jan LY, Jan YN. 2004. APC and GSK-3 $\beta$ are involved in mPar3 targeting to the nascent axon and establishment of neuronal polarity. Curr Biol 14: 2025-2032.

Siegrist SE, Doe CQ. 2007. Microtubule-induced cortical cell polarity. Genes Dev 21: 483-496.

Song AH, Wang D, Chen G, Li Y, Luo J, Duan S, Poo MM. 2009. A Selective Filter for Cytoplasmic Transport at the Axon Initial Segment. Cell 136: 1148-1160.

Stradal TE, Rottner K, Disanza A, Confalonieri S, Innocenti M, Scita G. 2004. Regulation of actin dynamics by WASP and WAVE family proteins. Trends Cell Biol 14: 303-311.

Strasser GA, Rahim NA, VanderWaal KE, Gertler FB, Lanier LM. 2004. Arp2/3 is a negative regulator of growth cone translocation. Neuron 43: 81-94.

Sweet ES, Firestein BL. 2008. Neuronal polarization: Old cells can learn new tricks. Curr Biol 18: 661-663.

Takahashi D, Yu W, Baas PW, Kawai-Hirai R, Hayashi K. 2007. Rearrangement of microtubule polarity orientation during conversion of dendrites to axons in cultured pyramidal neurons. Cell Motil Cytoskeleton 64: 347-359.

Takenawa T, Miki H. 2001. WASP and WAVE family proteins: Key molecules for rapid rearrangement of cortical actin filaments and cell movement. J Cell Sci 114: $1801-1809$.

Takenawa T, Suetsugu S. 2007. The WASP-WAVE protein network: Connecting the membrane to the cytoskeleton. Nat Rev Mol Cell Biol 8: 37-48.

Tohda C, Nakanishi R, Kadowaki M. 2006. Learning deficits and agenesis of synapses and myelinated axons in phosphoinositide-3 kinase-deficient mice. Neurosignals 15: $293-306$.

Toriyama M, Shimada T, Kim KB, Mitsuba M, Nomura E, Katsuta K, Sakumura Y, Roepstorff P, Inagaki N. 2006. Shootin1: A protein involved in the organization of an asymmetric signal for neuronal polarization. J Cell Biol 175: $147-157$.

Wang L, Zheng Y. 2007. Cell type-specific functions of Rho GTPases revealed by gene targeting in mice. Trends Cell Biol 17: 58-64.

Watabe-Uchida M, John KA, Janas JA, Newey SE, Van Aelst L. 2006. The Rac activator DOCK7 regulates neuronal 
polarity through local phosphorylation of stathmin/ Op18. Neuron 51: 727-739.

Wedlich-Soldner R, Altschuler S, Wu L, Li R. 2003 Spontaneous cell polarization through actomyosinbased delivery of the Cdc42 GTPase. Science 299: 1231-1235.

Westermann S, Weber K. 2003. Post-translational modifications regulate microtubule function. Nat Rev $\mathrm{Mol} \mathrm{Cell}$ Biol 4: 938-947.

Whitford KL, Dijkhuizen P, Polleux F, Ghosh A. 2002. Molecular control of cortical dendrite development Annu Rev Neurosci 25: 127-149.

Witke W, Sutherland JD, Sharpe A, Arai M, Kwiatkowski DJ. 2001. Profilin I is essential for cell survival and cell division in early mouse development. Proc Natl Acad Sci 98: $3832-3836$.

Witte H, Bradke F. 2008. The role of the cytoskeleton during neuronal polarization. Curr Opin Neurobiol 18: 479-487.

Witte H, Neukirchen D, Bradke F. 2008. Microtubule stabilization specifies initial neuronal polarization. J Cell Biol 180: 619-632.

Wittmann T, Bokoch GM, Waterman-Storer CM. 2004. Regulation of microtubule destabilizing activity of
Op18/stathmin downstream of Rac1. J Biol Chem 279: 6196-6203.

Yan D, Guo L, Wang Y. 2006. Requirement of dendritic Akt degradation by the ubiquitin-proteasome system for neuronal polarity. J Cell Biol 174: 415-424.

Yokota Y, Ring C, Cheung R, Pevny L, Anton ES. 2007. Nap1-regulated neuronal cytoskeletal dynamics is essential for the final differentiation of neurons in cerebral cortex. Neuron 54: 429-445.

Yoshimura T, Arimura N, Kaibuchi K. 2006. Signaling networks in neuronal polarization. J Neurosci 26: 10626-10630.

Yoshimura T, Kawano Y, Arimura N, Kawabata S, Kikuchi A, Kaibuchi K. 2005. GSK-3 $\beta$ regulates phosphorylation of CRMP-2 and neuronal polarity. Cell 120: 137-149.

Zhou FQ, Snider WD. 2005. Cell biology. GSK-3 $\beta$ and microtubule assembly in axons. Science 308: 211-214.

Zmuda JF, Rivas RJ. 1998. The Golgi apparatus and the centrosome are localized to the sites of newly emerging axons in cerebellar granule neurons in vitro. Cell Motil Cytoskeleton 41: 18-38.

Zolessi FR, Poggi L, Wilkinson CJ, Chien CB, Harris WA. 2006. Polarization and orientation of retinal ganglion cells in vivo. Neural Dev 1: 2. 


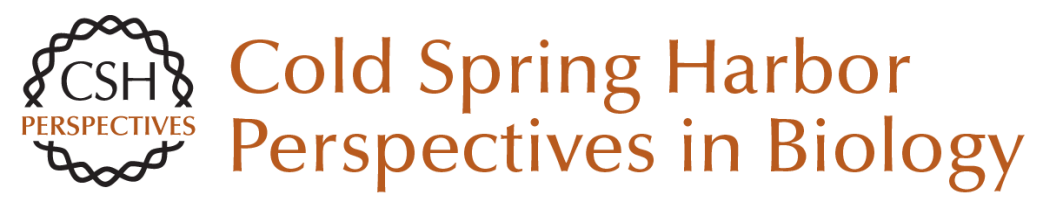

\section{Neuronal Polarity}

Sabina Tahirovic and Frank Bradke

Cold Spring Harb Perspect Biol 2009; doi: 10.1101/cshperspect.a001644 originally published online August 12, 2009

Subject Collection Symmetry Breaking in Biology

Cytoskeletal Mechanisms for Breaking Cellular Symmetry

R. Dyche Mullins

Symmetry Breaking in Biology

Rong Li and Bruce Bowerman

Planar Cell Polarity Signaling: The Developing

Cell's Compass

Eszter K. Vladar, Dragana Antic and Jeffrey D. Axelrod

Cellular Polarity in Prokaryotic Organisms Jonathan Dworkin

Symmetry Breaking in Plants: Molecular Mechanisms Regulating Asymmetric Cell

Divisions in Arabidopsis Jalean J. Petricka, Jaimie M. Van Norman and Philip N. Benfey

The Signaling Mechanisms Underlying Cell

Polarity and Chemotaxis Fei Wang

Polarization of Drosophila Neuroblasts During Asymmetric Division Kenneth E. Prehoda

Physical Model of Cellular Symmetry Breaking Jasper van der Gucht and Cécile Sykes
Polarity in Stem Cell Division: Asymmetric Stem

Cell Division in Tissue Homeostasis

Yukiko M. Yamashita, Hebao Yuan, Jun Cheng, et al.

Symmetry Breaking in the Life Cycle of the

Budding Yeast

Brian D. Slaughter, Sarah E. Smith and Rong Li

Neuronal Polarity

Sabina Tahirovic and Frank Bradke

Membrane Organization and Dynamics in Cell

Polarity Kelly Orlando and Wei Guo

Cellular Symmetry Breaking during

Caenorhabditis elegans Development Edwin Munro and Bruce Bowerman

Symmetry Breaking During Drosophila Oogenesis Siegfried Roth and Jeremy A. Lynch

Widely Conserved Signaling Pathways in the Establishment of Cell Polarity Luke Martin McCaffrey and lan G. Macara

Shaping Fission Yeast with Microtubules Fred Chang and Sophie G. Martin

For additional articles in this collection, see http://cshperspectives.cshlp.org/cgi/collection/

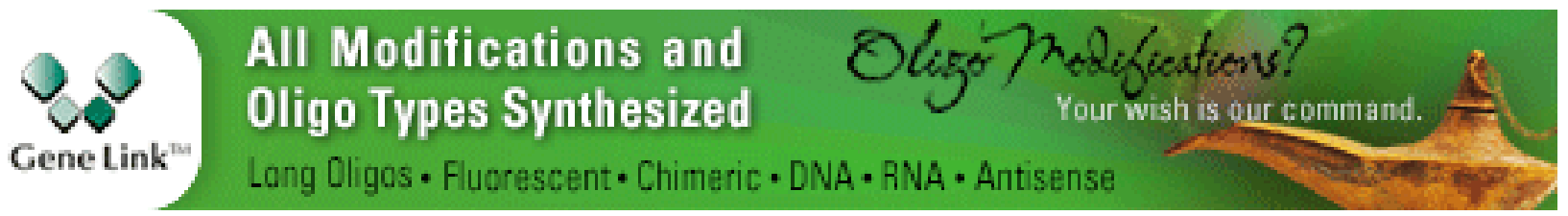

Copyright @ 2009 Cold Spring Harbor Laboratory Press; all rights reserved 